Editorial

\title{
Acknowledgment to Reviewers of Reports in 2021
}

\author{
Reports Editorial Office
}

Citation: Reports Editorial Office.

Acknowledgment to Reviewers of

Reports in 2021. Reports 2022, 5, 4.

https://doi.org/10.3390/reports

5010004

Published: 27 January 2022

Publisher's Note: MDPI stays neutral with regard to jurisdictional claims in published maps and institutional affiliations.

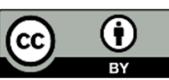

Copyright: $\odot 2022$ by the author. Licensee MDPI, Basel, Switzerland. This article is an open access article distributed under the terms and conditions of the Creative Commons Attribution (CC BY) license (https://creativecommons.org/licenses/by/4.0/).
MDPI AG, St. Alban-Anlage 66, 4052 Basel, Switzerland

Rigorous peer-reviews are the basis of high-quality academic publishing. Thanks to the great efforts of our reviewers, Reports was able to maintain its standards for the high quality of its published papers. Thanks to the contribution of our reviewers, in 2021, the median time to first decision was 20 days and the median time to publication was 45 days. The editors would like to extend their gratitude and recognition to the following reviewers for their precious time and dedication, regardless of whether the papers they reviewed were finally published:

\begin{tabular}{ll} 
Amalinei, Cornelia & Krajewska-Włodarczyk, Magdalena \\
Angelini, Paola & Kron, Philipp \\
Arotăriței, Dragos & Kujdowicz, Monika \\
Bazanova, Olga Mikhailovna & Kurien, Biji T. \\
Broecker, Felix & Lajolo, Carlo \\
Brown, Geoffrey & Lang, Roland \\
Brundage, Cord M. & Lechel, Andre \\
Bruschini, Luca & Lezine, DeQuincy A. \\
Cacialli, Pietro & Lok, Hiu Chuen \\
Chung, Ching-Hu & Martins, Luís \\
Cicero, Arrigo & Matei, Daniela Maria \\
Clemens, Robert K. & Mo, Chenglin \\
Contini, Carlo & Nakahari, Takashi \\
Devesa, Jesús & O'Grady, Mathew \\
Doddamani, Rajiv & Olivero, Antonella \\
Doretto, Paolo & O'Shaughnessy, Douglas \\
Endersby, Raelene & Pasek, Jarosław \\
Feher, Gergely & Patil, Shankargouda \\
Fionda, Bruno & Pepi, Milva \\
Ghanim, Bahil & Polano, Maurizio \\
Giannouli, Vaitsa & Popescu, Mihaela R. \\
Glover, Anthony & Potaczek, Daniel P. \\
Halachmi, Sarel & Rada, Miran \\
Hasan, Imtiaj & Ramaraj, Pandurangan \\
Hill, Christopher & Ramasauskaite, Diana \\
Jackson, Claire L. & Rigby, Matthew H. \\
Klinkhammer-Schalke, Monika & Rizzo, Alessandro \\
Kobeissy, Firas & Rodríguez Villanueva, Javier \\
Kolostova, Katarina & Saha, Nirmalya \\
\hline & \\
\hline
\end{tabular}


Sergi, Consolato

Singh, Sukhvinder

Slominski, Andrzej

Socea, Bogdan

Solimando, Antonio G.

Stachowska, Ewa

Sung, Wen-Wei
Testarelli, Luca

Vasiljeva, Marina

Versino, Elisabetta

Vinci, Concetto Paolo

Xiong, Jia

Zolotukhin, Denis B.

Zotti, Francesca 